\title{
Total Graphs of Idealization
}

\author{
D.Eswara Rao \\ Research scholar \\ Department of Mathematics \\ S.V.University, Tirupathi
}

\author{
D.Bharathi, Ph.D \\ Asso. Prof. of Mathematics \\ Department of Mathematics \\ S.V.University, Tirupathi
}

\begin{abstract}
Let $\mathrm{R}$ be a commutative ring with $\mathrm{Z}(\mathrm{R})$, its set of zero divisors. The total zero divisor graph of $R$, denoted $Z(\Gamma(R))$ is the undirected (simple) graph with vertices $Z(R)^{*}=Z(R)-\{0\}$, the set of nonzero zero divisors of $R$. and for distinct $x, y \in$ $z(R)^{*}$, the vertices $x$ and $y$ are adjacent if and only if $x+y \in$ $\mathrm{z}(\mathrm{R})$. In this paper prove that let $\mathrm{R}$ is commutative ring such that $\mathrm{Z}(\mathrm{R})$ is not ideal of $\mathrm{R}$ then $\mathrm{Z}(\Gamma(\mathrm{R}(+) \mathrm{M}))$ is connected with $\operatorname{diam}(\mathrm{Z}(\Gamma(\mathrm{R}(+) \mathrm{M})))=2$ and the sub graphs $\mathrm{Z}(\Gamma(\mathrm{R}(+) \mathrm{M}))$ and $\operatorname{Reg}(\Gamma(\mathrm{R}(+) \mathrm{M}))$ of $\mathrm{T}(\Gamma(\mathrm{R}(+) \mathrm{M}))$ are not disjoint. And also prove that let $\mathrm{R}$ be a commutative ring such that $\mathrm{Z}(\mathrm{R})$ is not an ideal of $\mathrm{R}$ with $\mathrm{Z}(\mathrm{R}(+) \mathrm{M})=\mathrm{Z}(\mathrm{R})(+) \mathrm{M}$ and $\mathrm{Reg}(\mathrm{R}(+) \mathrm{M})=$ $\operatorname{Reg}(\mathrm{R})(+) \mathrm{M}$ then $\mathrm{Z}(\Gamma(\mathrm{R}(+) \mathrm{M}))$ is connected if and only if $\mathrm{Z}(\Gamma(\mathrm{R})$ is connected and $\operatorname{Reg}(\Gamma(\mathrm{R}(+) \mathrm{M}))$ is connected if and only if $\operatorname{Reg}(\Gamma(\mathrm{R})$.
\end{abstract}

\section{Keywords}

Zerodivisors, Total zerodivisor graph of idealization, commutative ring, connected graph.

\section{INTRODUCTION}

Let $\mathrm{R}$ be a commutative Ring with non zero unity. The concept of the graph of the zero divisors of $\mathrm{R}$ was first introduced by Beck [1], where he was mainly interested in coloring. In his work all elements of the ring were vertices of the graph. The investigation of colorings of a commutative ring was then continued by D. D. Anderson and Naseer [2], In [3], D. F. Anderson and Livingston associate a graph, $\Gamma(\mathrm{R})$, to $\mathrm{R}$ with vertices $\mathrm{Z}(\mathrm{R})^{*}=\mathrm{Z}(\mathrm{R}) \backslash\{0\}$, the set of non zero zero divisors of $R$, and for distinct $x, y \in Z(R) \backslash\{0\}$. The vertices $x$ and $y$ are adjacent if $x y=0$. In [5] D.F. Anderson and Badawi introduced the total graph of $\mathrm{R}$, denoted by $\mathrm{T}(\Gamma(\mathrm{R}))$ as the graph with all elements of $R$ as vertices, and for distinct $x, y \in$ $\mathrm{R}$ are adjacent if $\mathrm{x}+\mathrm{y} \in \mathrm{Z}(\mathrm{R})$, and studied some graphical parameters of this graph such as diameter and girth.

In this paper studied some results of Total graphs of idealizations. In [5] D.F.Anderson, A.Badawi studied connectedness of Total graph of the idealization $\mathrm{R}(+) \mathrm{M}$ and also investigate diameter and has proved some results on girth of Total graphs. Different aspects of the idealization are thoroughly investigated in [10],[11]. In this paper also extend the study of D.F.Anderson, and A.Badawi. In this proved that let $R$ is commutative ring such that $Z(R)$ is not ideal of $R$ then $\mathrm{Z}(\Gamma(\mathrm{R}(+) \mathrm{M}))$ is connected with $\operatorname{diam}(\mathrm{Z}(\Gamma(\mathrm{R}(+) \mathrm{M})))=2$ and the sub graphs $\mathrm{Z}(\Gamma(\mathrm{R}(+) \mathrm{M}))$ and $\operatorname{Reg}(\Gamma(\mathrm{R}(+) \mathrm{M}))$ of $\mathrm{T}(\Gamma(\mathrm{R}(+) \mathrm{M}))$ are not disjoint. And also proved that let $\mathrm{R}$ be a commutative ring such that $\mathrm{Z}(\mathrm{R})$ is not an ideal of $\mathrm{R}$ with $\mathrm{Z}(\mathrm{R}(+) \mathrm{M})=\mathrm{Z}(\mathrm{R})(+) \mathrm{M}$ and $\operatorname{Reg}(\mathrm{R}(+) \mathrm{M})=\operatorname{Reg}(\mathrm{R})(+) \mathrm{M}$ then $\mathrm{Z}(\Gamma(\mathrm{R}(+) \mathrm{M}))$ is connected if and only if $\mathrm{Z}(\Gamma(\mathrm{R})$ is connected and $\operatorname{Reg}(\Gamma(\mathrm{R}(+) \mathrm{M}))$ is connected if and only if $\operatorname{Reg}(\Gamma(\mathrm{R})$ and also investigate the diameter and girth of $\operatorname{Reg}(\Gamma(\mathrm{R}(+) \mathrm{M}))$ that is $\operatorname{diam}(\operatorname{Reg}(\Gamma(\mathrm{R}(+) \mathrm{M}))) \leq 4$ if $\operatorname{Reg}(\Gamma(\mathrm{R}(+) \mathrm{M}))$ contains a cycle and $\operatorname{diam}(\operatorname{Reg}(\Gamma(\mathrm{R}(+) \mathrm{M}))) \leq 2$ if $\operatorname{Reg}(\Gamma(\mathrm{R}(+) \mathrm{M}))$ is connected.

\section{Preliminaries}

Complete Graph: A graph G in which every vertex is adjacent to every other vertex is called a complete graph. Complete graph is represented as $K_{n}$ where $n$ is the number of vertices in $K_{n}$.

Connected Graph: A graph $G$ is said to be a connected graph if there is at least one path between every pair of vertices in $\mathrm{G}$. otherwise $\mathrm{G}$ is said to be a disconnected graph.

Distance: Any two distinct vertices a and $b$ in graph $G$ , the distance between $a$ and $b$, denoted by $d(a, b)$ is the length of a shortest path connecting $a$ and $b$,if such a path exist. Otherwise $d(G)=\infty$

Diameter of G: $\operatorname{diam}(\mathrm{G})=\operatorname{Sup}\{\mathrm{d}(\mathrm{x}, \mathrm{y}) / \mathrm{x} \& \mathrm{y}$ are distinct vertices in $G$, where $d(x, y)$ is the length of shortest path from $x$ to $y$ in $G$. if there is no such a path then $d(x, y)=$ $\infty$.

The girth of G: The girth of $\mathrm{G}$ is denoted by $\operatorname{gr}(\mathrm{G})$ is length of shortest cycle in $G$. if $G$ contains no cycles the $\operatorname{gr}(\mathrm{G})=\infty$.

Path: A trail in which all the vertices are distinct is called a path.

Cycle: A path whose origin and terminus vertices are the same is called a cycle.

The idealization of $\mathbf{M}$ over $\mathbf{R}$ : The idealization of $\mathrm{M}$ over $\mathrm{R}$ is the commutative ring formed from $\mathrm{R} \times \mathrm{M}$ by defining addition and multiplication as follows

(i) $\quad\left(r_{1}, m_{1}\right)+\left(r_{2}, m_{2}\right)=\left(r_{1}+r_{2}, m_{1}+m_{2}\right)$;

(ii) $\quad\left(r_{1}, m_{1}\right)\left(r_{2}, m_{2}\right)=\left(r_{1} r_{2}, r_{1} m_{2}+r_{2} m_{1}\right)$.

The idealization of $M$ in $R$, denoted by $R(+) M$, here assume that neither the ring nor the module is trivial. Observe that if $a \in Z(R)^{*}$, then $(a, m) \in Z(R(+) M)^{*}$ for all $m \in M$. To see this, consider $b \in Z(R)^{*}$ with $a b=0 . \quad$ If $b M=0$, then $(a, m)(b, 0)=0$. If $b M \neq 0$, then there exists some $n \in M$ such that $b n \neq 0$. Hence, $(a, m)(0, b n)=0$.

\section{MAIN RESULTS}

Let $\mathrm{M}$ be an R-module, showed some results about the graph of idealization $\mathrm{R}(+) \mathrm{M}$. In this paper assume that $\mathrm{Z}(\mathrm{R}(+) \mathrm{M})=\mathrm{Z}(\mathrm{R})+\mathrm{M}$. Note that $\mathrm{Z}(\mathrm{R}(+) \mathrm{M}) \subseteq \mathrm{Z}(\mathrm{R})+\mathrm{M}$ always holds. But inclusion may be proper since $Z\left(\mathbb{Z}(+) \mathbb{Z}_{2}\right)=2 \mathbb{Z}+\mathbb{Z}_{2}$ However equality holds if either $M$ is an ideal of $R$ or $R$ is an integral domain and $\mathrm{M}$ is torsion free.

The following results are some basic results in[5]. 
Theorem : Let $\mathrm{R}$ be a commutative ring such that $\mathrm{Z}(\mathrm{R})$ is not an ideal of $\mathrm{R}$ and let $\mathrm{M}$ be an $\mathrm{R}$-module such that $\mathrm{Z}(\mathrm{R}(+) \mathrm{M})=\mathrm{Z}(\mathrm{R})+\mathrm{M}$

(i) $\mathrm{T}(\Gamma(\mathrm{R}(+) \mathrm{M}))$ is connected if and only if $\mathrm{T}(\Gamma(\mathrm{R}))$ is connected

(ii) $\operatorname{diam}(\mathrm{T}(\Gamma(\mathrm{R}(+) \mathrm{M})))=\operatorname{diam}(\mathrm{T}(\Gamma(\mathrm{R})))$

In the view of the above theorem have the following corollary.

Corollary: Let $\mathrm{R}$ be a commutative ring such that $\mathrm{Z}(\mathrm{R})$ is not an ideal of $\mathrm{R}$ and let $\mathrm{M}$ be an $\mathrm{R}$-module if $\mathrm{T}(\Gamma(\mathrm{R}))$ is connected then $\mathrm{T}(\Gamma(\mathrm{R}(+) \mathrm{M}))$ is connected with $\operatorname{diam}(\mathrm{T}(\Gamma(\mathrm{R}(+) \mathrm{M}))) \leq \operatorname{diam}(\mathrm{T}(\Gamma(\mathrm{R})))$.

The following is an example of a commutative ring $\mathrm{R}$ such that $\mathrm{Z}(\mathrm{R})$ is not an ideal of $\mathrm{R}$. both $\mathrm{T}(\Gamma(\mathrm{R}))$ and $\mathrm{T}(\Gamma(\mathrm{R}(+) \mathrm{M}))$ are connected, but $\operatorname{diam}(\mathrm{T}(\Gamma(\mathrm{R})))<\operatorname{diam}(\mathrm{T}(\Gamma(\mathrm{R}(+) \mathrm{M})))$. Thus the hypothesis that $\mathrm{Z}(\mathrm{R}(+) \mathrm{M})=\mathrm{Z}(\mathrm{R})+\mathrm{M}$ is needed in above theorem and the inequality in corollary above may strict.

In this paper investigate the diameter and connectedness of sub graphs which are $\mathrm{Z}(\Gamma(\mathrm{R}(+) \mathrm{M})), \operatorname{Reg}(\Gamma(\mathrm{R}(+) \mathrm{M}))$ and $\operatorname{Nil}(\Gamma(\mathrm{R}(+) \mathrm{M}))$.

Theorem : Let $\mathrm{R}$ be a commutative ring such that $\mathrm{Z}(\mathrm{R})$ is not an ideal of $\mathrm{R}$

(i) $\mathrm{Z}(\Gamma(\mathrm{R}(+) \mathrm{M}))$ is connected with $\operatorname{diam}(\mathrm{Z}(\Gamma(\mathrm{R}(+) \mathrm{M})))=2$.

(ii) some vertex of $\mathrm{Z}(\Gamma(\mathrm{R}(+) \mathrm{M}))$ is adjacent to a vertex of $\operatorname{Reg}(\Gamma(\mathrm{R}(+) \mathrm{M}))$. In particular, the subgraphs $\mathrm{Z}(\Gamma(\mathrm{R}(+) \mathrm{M}))$ and $\mathrm{Reg}(\Gamma(\mathrm{R}(+) \mathrm{M}))$ of $\mathrm{T}(\Gamma(\mathrm{R}(+) \mathrm{M}))$ are not disjoint.

(iii) if $\operatorname{Reg}(\Gamma(\mathrm{R}(+) \mathrm{M}))$ is connected then $\mathrm{T}(\Gamma(\mathrm{R}(+) \mathrm{M}))$ is connected.

Proof : (i) each $(x, a) \in Z(R(+) M) *$ is adjacent to $(0,0)$ thus $(x, a)-(0,0)-(y, b)$ is a path in $\mathrm{Z}(\mathrm{R}(+) \mathrm{M})$ of length two between any distinct $(\mathrm{x}, \mathrm{a}),(\mathrm{y}, \mathrm{b}) \in \mathrm{Z}(\mathrm{R}(+) \mathrm{M}) *$.

Moreover there are non adjacent $(\mathrm{x}, \mathrm{a}),(\mathrm{y}, \mathrm{b}) \in \mathrm{Z}(\mathrm{R}(+) \mathrm{M}) *$ since $\mathrm{Z}(\mathrm{R}(+) \mathrm{M})=\mathrm{Z}(\mathrm{R})+\mathrm{M}$ and $\mathrm{Z}(\mathrm{R})$ is not an ideal of $\mathrm{R}$

So $\operatorname{diam}(\mathrm{Z}(\Gamma(\mathrm{R}(+) \mathrm{M})))=2$.

(ii) since $\mathrm{Z}(\mathrm{R})$ is not an ideal of $\mathrm{R}$ there are distinct $(\mathrm{x}, \mathrm{a}),(\mathrm{y}, \mathrm{b}) \in \mathrm{Z}(\mathrm{R}(+) \mathrm{M})^{*} \quad$ such that $\quad(\mathrm{x}, \mathrm{a})+(\mathrm{y}, \mathrm{b}) \in$ $\operatorname{Reg}(\mathrm{R}(+) \mathrm{M})$.

Then $(-x,-a) \in Z(R(+) M)$ and $(x, a)+(y, b) \in R \operatorname{Reg}(R(+) M)$ are adjacent in $\mathrm{T}(\Gamma(\mathrm{R}(+) \mathrm{M}))$.

Since $(-x,-a)+(x, a)+(y, b)=(y, b) \in Z(R(+) M)^{*}$.

The subgraphs $\mathrm{Z}(\Gamma(\mathrm{R}(+) \mathrm{M}))$ and $\operatorname{Reg}(\Gamma(\mathrm{R}(+) \mathrm{M}))$ of $\mathrm{T}(\Gamma(\mathrm{R}(+) \mathrm{M}))$ are not disjoint.

(iii) Suppose that $\operatorname{Reg}(\Gamma(\mathrm{R}(+) \mathrm{M}))$ connected.

Since $\mathrm{Z}(\Gamma(\mathrm{R}(+) \mathrm{M}))$ is also connected by part (i) above it is sufficient to show that there is a path form $(x, a)$ to $(y, b)$ in $\mathrm{T}(\Gamma(\mathrm{R}(+) \mathrm{M}))$.

For any $(\mathrm{x}, \mathrm{a}) \in \mathrm{Z}(\mathrm{R}(+) \mathrm{M})$ and $(\mathrm{y}, \mathrm{b}) \in \mathrm{Reg}(\mathrm{R}(+) \mathrm{M})$
By part (ii) above there are adjacent vertices $(\mathrm{z}, \mathrm{c})$ and $(\mathrm{w}, \mathrm{d})$ in $\mathrm{Z}(\Gamma(\mathrm{R}(+) \mathrm{M}))$ and $\operatorname{Reg}(\Gamma(\mathrm{R}(+) \mathrm{M}))$ respectively.

Since $\mathrm{Z}(\Gamma(\mathrm{R}(+) \mathrm{M}))$ is connected there is a path from $(\mathrm{x}, \mathrm{a})$ to $(\mathrm{z}, \mathrm{c})$ in $\mathrm{Z}(\Gamma(\mathrm{R}(+) \mathrm{M}))$ and

Since $\operatorname{RegZ}(\Gamma(\mathrm{R}(+) \mathrm{M}))$ is connected there is a path from $(w, d)$ to $(y, b)$ in $\operatorname{Reg}(\Gamma(R(+) M))$

As $(\mathrm{z}, \mathrm{c})$ and $(\mathrm{w}, \mathrm{d})$ are adjacent in $\mathrm{T}(\Gamma(\mathrm{R}(+) \mathrm{M}))$.

$\therefore \quad$ There is a path from $(\mathrm{x}, \mathrm{a})$ to $(\mathrm{y}, \mathrm{b})$ in $\mathrm{T}(\Gamma(\mathrm{R}(+) \mathrm{M}))$

Thus $\mathrm{T}(\mathrm{\Gamma}(\mathrm{R}(+) \mathrm{M}))$ is connected

Theorem : Let $\mathrm{M}$ be an $\mathrm{R}$-module such that $\mathrm{Z}(\mathrm{M}) \subseteq \mathrm{Z}(\mathrm{R})$ then the following condition are equivalen

(i) $\mathrm{Z}(\mathrm{R}(+) \mathrm{M})$ is an ideal of $\mathrm{R}(+) \mathrm{M}$

(ii) $\mathrm{Z}(\mathrm{R})$ is an ideal of $\mathrm{R}$, in addition to that $\mathrm{Z}(\mathrm{R}(+) \mathrm{M})=\mathrm{Z}(\mathrm{R})+\mathrm{M}$.

Proof : Let us first suppose that $\mathrm{Z}(\mathrm{R})$ is an ideal of $\mathrm{R}$

Since $\mathrm{Z}(\mathrm{M}) \subseteq \mathrm{Z}(\mathrm{R})$ then $\mathrm{Z}(\mathrm{R}) \mathrm{U} \mathrm{Z}(\mathrm{M})=\mathrm{Z}(\mathrm{R})$ and therefore $\mathrm{Z}(\mathrm{R}(+) \mathrm{M})=\mathrm{Z}(\mathrm{R})+\mathrm{M}$.

The set on the right hand side is an ideal according to [5] theorem 3.1

suppose that $\mathrm{Z}(\mathrm{R}(+) \mathrm{M})$ is an ideal of $\mathrm{R}(+) \mathrm{M}$ and let $\mathrm{z}_{1}, \mathrm{z}_{2} \in$ $\mathrm{Z}(\mathrm{R})$.

then $\left(\mathrm{z}_{1}, 0\right),\left(\mathrm{z}_{2}, 0\right) \in \mathrm{Z}(\mathrm{R})+\mathrm{M}$ so $\left(\mathrm{z}_{1}+\mathrm{z}_{2}, 0\right) \in \mathrm{Z}(\mathrm{R})+\mathrm{M}$

from this conclude that $\mathrm{z}_{1}+\mathrm{Z}_{2} \in \mathrm{Z}(\mathrm{R}) \cup \mathrm{Z}(\mathrm{M})=\mathrm{Z}(\mathrm{R})$

likewise if $r \in R$ and $\mathrm{z} \in \mathrm{Z}(\mathrm{R})$ then $(\mathrm{r}, 0) \in \mathrm{R}(+) \mathrm{M}$ and $(\mathrm{z}, 0) \in$ $\mathrm{Z}(\mathrm{R}(+) \mathrm{M})$

consequently $(\mathrm{r}, 0) \cdot(\mathrm{z}, 0)=(\mathrm{rz}, 0) \in \mathrm{Z}(\mathrm{R}(+) \mathrm{M}$ and have $\mathrm{rz} \in$ $\mathrm{Z}(\mathrm{R}) \cup \mathrm{Z}(\mathrm{M})=\mathrm{Z}(\mathrm{R})$.

Theorem : Let $\mathrm{R}$ be a commutative ring such that $\mathrm{Z}(\mathrm{R})$ is not an ideal of $R$, Let $M$ be an R-module such that $\mathrm{Z}(\mathrm{R}(+) \mathrm{M})=\mathrm{Z}(\mathrm{R})+\mathrm{M}$ and $\mathrm{Reg}(\mathrm{R}(+) \mathrm{M})=\mathrm{Reg}(\mathrm{R})+\mathrm{M}$

(i) $\mathrm{Z}(\Gamma(\mathrm{R}(+) \mathrm{M}))$ is connected if and only if $\mathrm{Z}(\Gamma(\mathrm{R}))$ is connected

(ii) $\operatorname{Reg}(\Gamma(\mathrm{R}(+) \mathrm{M}))$ is connected if and only if $\operatorname{Reg}(\Gamma(\mathrm{R}))$ is connected.

Proof : (i) suppose that $\mathrm{Z}(\Gamma(\mathrm{R}(+) \mathrm{M}))$ connected

Let $\mathrm{x}, \mathrm{y} \in \mathrm{Z}(\mathrm{R})$ be distinct then $(\mathrm{x}, 0),(\mathrm{y}, 0) \in \mathrm{Z}(\mathrm{R})+\mathrm{M}$.

So there is a path $(\mathrm{x}, 0)-\left(\mathrm{s}_{1}, \mathrm{t}_{1}\right)-\left(\mathrm{s}_{2}, \mathrm{t}_{2}\right)-\ldots \ldots \ldots \ldots \ldots\left(\mathrm{s}_{\mathrm{n}}, \mathrm{t}_{\mathrm{n}}\right)-(\mathrm{y}, 0)$ from $(\mathrm{x}, 0)$ to $(\mathrm{y}, 0)$ in $\mathrm{Z}(\Gamma(\mathrm{R}(+) \mathrm{M}))$

Since $Z(R(+) M)=Z(R)+M$ conclude that $x-s_{1}-s_{2}-\ldots \ldots \ldots .-s_{n}-$ $y$ is a path from $x$ to $y$ in $Z(\Gamma(R))$

Thus $\mathrm{Z}(\Gamma(\mathrm{R}))$ is connected.

Conversely $\mathrm{Z}(\Gamma(\mathrm{R}))$ is connected 
$(x, a),(y, b) \in R(+) M$ be distinct. Then there is a path $x-s_{1}-s_{2}-$ $\ldots \ldots \ldots .-\mathrm{S}_{\mathrm{n}}-\mathrm{y}$ is a path from $\mathrm{x}$ to $\mathrm{y}$ in $\mathrm{Z}(\Gamma(\mathrm{R}))$

Since $\mathrm{Z}(\mathrm{R})+\mathrm{M} \subseteq \mathrm{Z}(\mathrm{R}(+) \mathrm{M})$ have

$(\mathrm{x}, \mathrm{a})-\left(\mathrm{s}_{1}, 0\right)-\left(\mathrm{s}_{2}, 0\right)-$ $.\left(s_{n}, 0\right)-(y, b)$ from $(x, a)$ to $(y, b)$

in $\mathrm{Z}(\Gamma(\mathrm{R}(+) \mathrm{M}))$

If $x=y$ then use path $(x, a)-(-x, 0)-$ $-(y, b)$

Thus $\mathrm{Z}(\Gamma(\mathrm{R}(+) \mathrm{M}))$ connected.

(ii) The proof of (ii) is follows directly from (i) by using $\operatorname{Reg}(\mathrm{R}(+) \mathrm{M})=\operatorname{Reg}(\mathrm{R})+\mathrm{M}$.

Example : Let $\mathrm{R}=\mathrm{M}=\mathrm{Z}_{2} \times \mathrm{Z}_{2}$ then $\mathrm{Z}(\mathrm{R})$ is not an ideal of $\mathrm{R}$ , $\mathrm{T}(\Gamma(\mathrm{R}))$ and $\mathrm{T}(\Gamma(\mathrm{R}(+) \mathrm{M}))$ are both connected and $\mathrm{Z}(\mathrm{R}(+) \mathrm{M})=\mathrm{Z}(\mathrm{R})+\mathrm{M}$.

Next assume that $\mathrm{Z}(\mathrm{R})$ is an ideal of $\mathrm{R}$.

Theorem : Let $\mathrm{R}$ be a commutative ring and Let $\mathrm{M}$ be a non zero R-module

(i) $\operatorname{gr}(\operatorname{Reg}(\Gamma(\mathrm{R}(+) \mathrm{M})))=3,4$ or $\infty$ in particular $\operatorname{gr}(\operatorname{Reg}(\Gamma(\mathrm{R}(+) \mathrm{M}))) \leq 4$ if $\operatorname{Reg}(\Gamma(\mathrm{R}(+) \mathrm{M}))$ contains a cycle.

(ii) $\operatorname{diam}(\operatorname{Reg}(\Gamma(\mathrm{R}(+) \mathrm{M})))=0,1,2$ or $\infty$ in particular $\operatorname{diam}(\operatorname{Reg}(\Gamma(\mathrm{R}(+) \mathrm{M}))) \leq 2$ if $\operatorname{Reg}(\Gamma(\mathrm{R}(+) \mathrm{M}))$ is connected.

Proof : (i) Suppose that $\operatorname{Reg}(\Gamma(\mathrm{R}(+) \mathrm{M}))$ contains a cycle

Since $\operatorname{Reg}(\Gamma(\mathrm{R}(+) \mathrm{M}))$ is disjoint union of either complete or complete bipartite graphs theorem 2.2 [ ]

It must contain either a 3-cycle or a 4- cycle

Thus $\operatorname{gr}(\operatorname{Reg}(\Gamma(\mathrm{R}(+) \mathrm{M}))) \leq 4$.

(ii) Suppose that $\operatorname{Reg}(\Gamma(\mathrm{R}(+) \mathrm{M}))$ connected

Then $\operatorname{Reg}(\Gamma(\mathrm{R}(+) \mathrm{M}))$ is a singleton, complete graph or a complete bipartite graph theorem 2.2 [ ]

Thus $\operatorname{diam}(\operatorname{Reg}(\Gamma(\mathrm{R}(+) \mathrm{M}))) \leq 2$.

Hence proof .

Example: (a) Let $R=\mathbb{Z}_{2} \times \mathbb{Z}_{3}$. Then it is easy to check that $\operatorname{gr}(\mathrm{Z}(\Gamma(\mathrm{R}(+) \mathrm{M})))=\operatorname{gr}(\mathrm{T}(\Gamma(\mathrm{R}(+) \mathrm{M})))=3$ and $\operatorname{gr}(\operatorname{Reg}(\Gamma(\mathrm{R}(+) \mathrm{M})))=\infty$

(b) Let $\mathrm{R}=\mathbb{Z}_{3} \times \mathbb{Z}_{4}$. Then it is easy to check that $\operatorname{gr}(\mathrm{Z}(\Gamma(\mathrm{R}(+) \mathrm{M})))=\operatorname{gr}(\mathrm{T}(\Gamma(\mathrm{R}(+) \mathrm{M})))=$ $\operatorname{gr}(\operatorname{Reg}(\Gamma(\mathrm{R}(+) \mathrm{M})))=3$.

Theorem : Let $\mathrm{R}$ be a commutative ring

(i) $\operatorname{Nil}(\Gamma(\mathrm{R}(+) \mathrm{M}))$ is complete (induced) subgraph of $\mathrm{Z}(\Gamma(\mathrm{R}(+) \mathrm{M}))$

(ii) each vertex of $\operatorname{Nil}(\Gamma(\mathrm{R}(+) \mathrm{M}))$ is adjacent to each distinct vertex of $\mathrm{Z}(\Gamma(\mathrm{R}(+) \mathrm{M}))$

(iii) $\operatorname{Nil}(\Gamma(\mathrm{R}(+) \mathrm{M}))$ is disjoint form $\operatorname{Reg}(\Gamma(\mathrm{R}(+) \mathrm{M}))$ (iv) if $0 \neq \mathrm{Nil}(\mathrm{R}(+) \mathrm{M}) \subseteq \mathrm{Z}(\mathrm{R}(+) \mathrm{M})$ then $\operatorname{gr}(\mathrm{Z}(\Gamma(\mathrm{R}(+) \mathrm{M})))=$

Proof : part (i) follows since $\mathrm{Nil}(\mathrm{R}(+) \mathrm{M}) \subseteq \mathrm{Z}(\mathrm{R}(+) \mathrm{M})$ is an ideal of $\mathrm{R}$

Part (ii) and (iii) follows from $\mathrm{Nil}(\mathrm{R}(+) \mathrm{M})+\mathrm{Z}(\mathrm{R}(+) \mathrm{M}) \subseteq$ $\mathrm{Z}(\mathrm{R}(+) \mathrm{M})$ and

$\mathrm{Nil}(\mathrm{R}(+) \mathrm{M})+\operatorname{Reg}(\mathrm{R}(+) \mathrm{M}) \subseteq \operatorname{Reg}(\mathrm{R}(+) \mathrm{M})$ for a commutative ring respectively.

(iv) Let $(\mathrm{x}, \mathrm{a}) \in \mathrm{Nil}(\mathrm{R}(+) \mathrm{M})^{*}$ and $(\mathrm{y}, \mathrm{b}) \in \mathrm{Z}(\mathrm{R}(+) \mathrm{M}) \backslash$ $\operatorname{Nil}(\mathrm{R}(+) \mathrm{M})$

Then $(0,0)-(\mathrm{x}, \mathrm{a})-(\mathrm{y}, \mathrm{b})-(0,0)$ is a path 3-cycle in $\mathrm{Z}(\mathrm{R}(+) \mathrm{M})$ by part (ii) above

So $\operatorname{gr}(\mathrm{Z}(\Gamma(\mathrm{R}(+) \mathrm{M})))=3$.

Example 3.20. (a) Let $\mathrm{R}=\mathrm{M}=\mathrm{Z}_{2} \times \mathrm{Z}_{2}$. Then $\mathrm{Z}(\mathrm{R})$ is not an ideal of $\mathrm{R}, \mathrm{T}(\Gamma(\mathrm{R}))$ and

$\mathrm{T}(\Gamma(\mathrm{R}(+) \mathrm{M}))$ are both connected, and $\mathrm{Z}(\mathrm{R}(+) \mathrm{M})=$ $\mathrm{Z}(\mathrm{R})(+) \mathrm{M}$. However, $\operatorname{gr}(\mathrm{T}(\Gamma(\mathrm{R}))) \neq$

$\operatorname{gr}(\mathrm{T}(\Gamma(\mathrm{R}(+) \mathrm{M})))$ since $\operatorname{gr}(\mathrm{T}(\Gamma(\mathrm{R}(+) \mathrm{M})))=3$ by Theorem $3.19(2)$ and $\operatorname{gr}(\mathrm{T}(\Gamma(\mathrm{R})))=4$.

(b) It is clear that $\operatorname{gr}(\mathrm{Z}(\Gamma(\mathrm{R}(+) \mathrm{M}))) \leq \operatorname{gr}(\mathrm{Z}(\Gamma(\mathrm{R})))$ and $\operatorname{gr}(\operatorname{Reg}(\Gamma(\mathrm{R}(+) \mathrm{M}))) \leq$

$\operatorname{gr}(\operatorname{Reg}(\Gamma(\mathrm{R})))$. However, both inequalities may be strict, even ifZ $(\mathrm{R}(+) \mathrm{M})=\mathrm{Z}(\mathrm{R})(+) \mathrm{M}$. For

example, let $\mathrm{R}=\mathrm{M}=\mathrm{Z3}$; then $\operatorname{gr}(\mathrm{Z}(\Gamma(\mathrm{R})))=\operatorname{gr}(\operatorname{Reg}(\Gamma(\mathrm{R})))=$ $\infty, \operatorname{gr}(\mathrm{Z}(\Gamma(\mathrm{R}(+) \mathrm{M})))=3$,

and $\operatorname{gr}(\operatorname{Reg}(\Gamma(\mathrm{R}(+) \mathrm{M})))=4$.

(c) If $|\mathrm{M}| \geq 3$, then $\operatorname{gr}(\operatorname{Reg}(\Gamma(\mathrm{R}(+) \mathrm{M})))=3$ or 4 by Theorem 3.19(2). Both values are possible. For example $\operatorname{gr}\left(\operatorname{Reg}\left(\Gamma\left(Z_{3}(+) Z_{3}\right)\right)\right)=4$ and $\operatorname{gr}\left(\operatorname{Reg}\left(\Gamma\left(Z_{2}(+) \mathbb{F}_{4}\right)\right)\right)=3$.

(d) If $2=|\mathrm{M}|<|\mathrm{R}|$, then $\operatorname{gr}(\operatorname{Reg}(\Gamma(\mathrm{T}(+) \mathrm{M})))=3$ or $\infty$ by Theorem 3.19(4). Both values are possible. For example, $\operatorname{gr}\left(\operatorname{Reg}\left(\Gamma \quad\left(\left(\mathrm{Z}_{2} \times \mathrm{Z}_{2}\right)(+) \mathrm{Z}_{2}\right)\right)\right)=\infty$ and $\operatorname{gr}(\operatorname{Reg}(\Gamma$ $(\mathrm{Z} 4(+) \mathrm{Z} 2)))=3$

Lemma: Let $\mathrm{R}(+) \mathrm{M}$ be an idealization of an $\mathrm{R}$-module $\mathrm{M}$ such that $\mathrm{Z}(\mathrm{R}(+) \mathrm{M})$ is not an ideal of $\mathrm{R}(+) \mathrm{M}$ then char( $\mathrm{R}(+) \mathrm{M})=2$ if and only if $2 \mathrm{Z}(\mathrm{R}(+) \mathrm{M})=\{0\}$

Proof: if char $(\mathrm{R}(+) \mathrm{M})=2$ then clearly $2 \mathrm{Z}(\mathrm{R}(+) \mathrm{M})=\{0\}$

Conversely suppose that $2 \mathrm{Z}(\mathrm{R}(+) \mathrm{M})=\{0\}$

i.e. $2(\mathrm{z}, \mathrm{a})=0$ for all $(\mathrm{z}, \mathrm{a}) \in \mathrm{Z}(\mathrm{R}(+) \mathrm{M})$

since $\mathrm{Z}(\mathrm{R}(+) \mathrm{M})$ is not an ideal of $\mathrm{R}$, there exists $(\mathrm{x}, \mathrm{b}),(\mathrm{y}, \mathrm{c}) \in$ $\mathrm{Z}(\mathrm{R}(+) \mathrm{M})$ such that

$(\mathrm{z}, \mathrm{a})=(\mathrm{x}, \mathrm{b})+(\mathrm{y}, \mathrm{c}) \in \operatorname{Reg}(\mathrm{R}(+) \mathrm{M})$

Then $2(\mathrm{z}, \mathrm{a})=2(\mathrm{x}, \mathrm{b})+2(\mathrm{y}, \mathrm{c})$

$$
=0+0 \quad[\text { since }(x, b),(y, c) \in Z(R(+) M)]
$$




$$
=0
$$

Therefore $2(\mathrm{z}, \mathrm{a})=0$ for all $(\mathrm{z}, \mathrm{a}) \in \operatorname{Reg}(\mathrm{R}(+) \mathrm{M})$

i.e. $\operatorname{char}(\mathrm{R}(+) \mathrm{M})=2$.

Theorem: Let $\mathrm{R}$ be a commutative ring such that $\mathrm{Z}(\mathrm{R}(+) \mathrm{M})$ is not an ideal of $\mathrm{R}$. then either gr $(\mathrm{Z}(\Gamma(\mathrm{R}(+) \mathrm{M}))=3$ or $\mathrm{gr}$ $(\mathrm{Z}(\Gamma(\mathrm{R}(+) \mathrm{M}))=\infty$. Moreover ,if gr $(\mathrm{Z}(\Gamma(\mathrm{R}(+) \mathrm{M}))=\infty$ then $\mathrm{R}(+) \mathrm{M} \cong \mathrm{Z}_{2}(+) \mathrm{M} \times \mathrm{Z}_{2}(+) \mathrm{M}$, so $\mathrm{Z}\left(\Gamma(\mathrm{R}(+) \mathrm{M})\right.$ is a $\mathrm{K}^{1,2}$ star graph with centre $(0,0)$.

Proof: if $(x, a)+(y, b) \quad \in Z(R(+) M) *$ for distinct $(x, a),(y, b)$ $\in Z(R(+) M)^{*}$ then $(0,0)-(x, a)-(y, b)-(0,0)$ is a 3 - cycle in $\mathrm{Z}(\Gamma(\mathrm{R}(+) \mathrm{M})$ so gr $(\mathrm{Z}(\Gamma(\mathrm{R}(+) \mathrm{M}))=3$.

Otherwise $(x, a)+(y, b) \in \operatorname{Reg}(R(+) M)$ for all distinct $(x, a),(y, b)$ $\in \mathrm{Z}(\mathrm{R}(+) \mathrm{M})^{*}$

So in this case $(x, a) \in Z(R(+) M) *$ is adjacent to $(0,0)$. And no distinct $(x, a),(y, b) \in Z(R(+) M)^{*}$ are adjacent.

Thus $\mathrm{Z}(\Gamma(\mathrm{R}(+) \mathrm{M})$ is a star graph with centre $(0,0)$.

So $\operatorname{gr}(\mathrm{Z}(\Gamma(\mathrm{R}(+) \mathrm{M}))=\infty$.

Let $\mathrm{Z}(\mathrm{R}(+) \mathrm{M})=\mathrm{U}_{\alpha \in \Lambda} P \alpha$ where each $\mathrm{P} \alpha$ is a prime ideal of $\mathrm{R}(+) \mathrm{M}$ Then $\mid \Lambda \geq$ since $\mathrm{Z}(\mathrm{R}(+) \mathrm{M})$ is not an ideal of $\mathrm{R}(+) \mathrm{M}$.

Assume gr $(\mathrm{Z}(\Gamma(\mathrm{R}(+) \mathrm{M}))=\infty$. Then $(\mathrm{x}, \mathrm{a})+(\mathrm{y}, \mathrm{b}) \in$ $\operatorname{Reg}(\mathrm{R}(+) \mathrm{M})$ for all distinct $(\mathrm{x}, \mathrm{a}),(\mathrm{y}, \mathrm{b}) \in \mathrm{Z}(\mathrm{R}(+) \mathrm{M})^{*}$ and thus $\left|\mathrm{P}_{\alpha}\right|=2$.

Hence the intersection of any two distinct $\mathrm{P}_{\alpha}{ }^{1} \mathrm{~s}$ is $\{0\}$ and thus $\mid \Lambda=2$.

So let $\mathrm{Z}(\mathrm{R}(+) \mathrm{M})=\mathrm{P}_{1} \cup \mathrm{P}_{2}$ for prime ideals $\mathrm{P}_{1}, \mathrm{P}_{2}$ of $\mathrm{R}(+) \mathrm{M}$ with $\mathrm{P}_{1} \cap \mathrm{P}_{2}=\{0\}$

And $\left|P_{1}\right|=\left|P_{2}\right|=2$. Hence $|\mathrm{Z}(\mathrm{R}(+) \mathrm{M})|=3$.

And thus $\mathrm{R}$ is also finite. so $\mathrm{P}_{1}$ and $\mathrm{P}_{2}$ are only prime(maximal) ideals of $\mathrm{R}$.

By the Chinese remainder theorem have

$\mathrm{R}(+) \mathrm{M} \cong \mathrm{R}(+) \mathrm{M} / \mathrm{P}_{1} \times \mathrm{R}(+) \mathrm{M} / \mathrm{P}_{2} \cong \mathrm{Z}_{2}(+) \mathrm{M} \times \mathrm{Z}_{2}(+) \mathrm{M}$.

\section{CONCLUSION}

In this paper defined Total graph of idealization of commutative ring and have discussed some basic results. Also investigated some properties diameter, girth of $\mathrm{Z}((\Gamma(\mathrm{R}(+) \mathrm{M})))$. This paper just an opening for making another bridge between graph theory and ring theory. The study of connectedness for the Total graphs and its sub graphs will be an interesting part of research. The development of concept of total graphs in any direction, will be an exciting field of research.

\section{REFERENCES}

[1] I.Beck, Coloring of commutative rings, J.Algebra 116(1988),208-226.

[2] D.D.Anderson,M.Naseer, Becks coloring of a commutative ring, J.Algebra,159(1993), 500-514.

[3] D.F. Anderson,P.S.Livingston, The zero divisor graph of a commutative ring J.Algebra, 217(1999),434-447.

[4] D.F. Anderson, A.Frazier,A.Lauve, P.Livingston ,The zero divisor graph of a commutative ring II , Lecture Notes in Pure and Appl.Math.,vol.220,Dekker,New York,2001,61-72.

[5] D.F. Anderson,A.Badawi, The total graph of commutative ring, J.Algebra,.320, 2706$2719,(2008)$

[6] F.R.DEMEYER,T.McKenzie and K.Schneider,the zero divisor graph of a commutative semigroup. Semigroup Forum,vol.65(2002),206-214.

[7] D.F. Anderson, A. Badawi, On the zero-divisor graph of a ring, Comm. Algebra 36 (2008) 3073-3092.

[8] D.F. Anderson, R. Levy, J. Shapiro, Zero-divisor graphs, von Neumann regular rings, and Boolean algebras, J. Pure Appl. Algebra 180 (2003) 221-241.

[9] D.F. Anderson, S.B. Mulay, On the diameter and girth of a zero-divisor graph, J. Pure Appl. Algebra 210 (2007) 543-550.

[10] M. Axtel, J. Coykendall, J. Stickles, Zero-divisor graphs of polynomials and power series over commutative rings, Comm. Algebra 33 (2005) 2043-2050

[11] M. Axtel, J. Stickles, Zero-divisor graphs of idealizations, J. Pure Appl. Algebra 204 (2006) 235-243.

[12] I. Kaplansky, Commutative Rings, rev. ed., University of Chicago Press, Chicago, 1974.

[13] J.D. LaGrange, Complemented zero-divisor graphs and Boolean rings, J. Algebra 315 (2007) 600-611.

[14] T.G. Lucas, The diameter of a zero-divisor graph, J. Algebra 301 (2006) 174-193.

[15] S. Akbari, A. Mohammadian, On the zero-divisor graph of a commutative ring,J.Algebra 274 (2004) 847-855. 